\title{
Metodologia para a pesquisa em artes performativas: encontrando elementos por meio de um experimento poético-teatral
}

VAGNER DE SOUZA VARGAS

\begin{abstract}
The academic research in the performing arts field is constantly in search of methodological approaches, as well as of terminologies that will provide a theoretical-reflexive framework that supports the singularities of its specificity as an area of knowledge. This article aims to present, briefly, some reflections on the methodology of ethnographic surrealism, related to a poetic-theatrical experiment used as field work in doctoral research in education. The work that used ethnographic surrealism in the performing arts research for the first time made it possible to understand, in an extended way, how the cognitive-affective-significative processes occur during the theatrical event. In addition, this study also proposed this methodology as a possible approach to this area of knowledge.
\end{abstract}

PERFORMING ARTS / ETHNOGRAPHIC SURREALISM / RESEARCH METHODOLOGY

INTRODUCุÃO

As artes performativas se configuram como área do conhecimento académico que ainda buscam por um maior espraiamento de suas peculiaridades epistémicas, assim como de abordagens metodológicas para o desenvolvimento de pesquisas que venham ao encontro de suas especificidades de área. Muitas metodologias tradicionalmente utilizadas nos estudos da grande área das ciências humanas e de outras ciências se prestam a abordagens investigativas que atendam a determinadas possibilidades de achados. Entretanto, aspetos específicos das artes performativas nem sempre se enquadram em tais possibilidades metodológicas, além de muitos enfoques tradicionais não conseguirem dar conta das necessidades empíricas e reflexivas suscitadas por essa área do conhecimento.

Nesse sentido, nos tempos atuais, é necessário que as pesquisas acadêmicas nas artes cênicas estejam abertas a inovações metodológicas, 
com o intuito de que seus estudos venham ao encontro das necessidades contemporâneas que os pesquisadores desta área têm demonstrado, sobretudo, nos últimos anos. Ainda parece ser novo e de difícil aceitação no contexto da pesquisa acadêmica que muitos artistas utilizem a sua própria realidade de trabalho em processo criativo ou quando em cena, como possibilidades metodológicas de campo empírico potentes a lhes fornecer elementos necessários a legitimar-se como arcabouço teórico-reflexivo-metodológico.

Dentro dessa perspetiva, estudos que se desenvolvam por meio de outras $^{16}$ possibilidades metodológicas, hibridizando as tradicionalmente utilizadas nas pesquisas acadêmicas, necessitam ser divulgados, estimulados e ter espaço dentro da academia no intuito de que possam vir a expor outras possibilidades aos campos do conhecimento (Vargas et al., 2019). Desse modo, se põe em xeque muito do que está estabelecido e institucionalmente normatizado como possibilidade de aceder e legitimar o conhecimento.

No que se refere especificamente ao campo das artes cênicas, pesquisas que busquem se desenvolver em uma interface entre teoria e prática, processos criativos e em cena, ou hibridizando todas essas possibilidades em diálogo com metodologias de pesquisas tradicionais das ciências humanas, encontrarão, em uma primeira instância, o árduo trabalho de se constituírem enquanto metodologias de pesquisa viáveis para atingir aos objetivos propostos e em diálogo com seus achados. Ao fazer isso, também há de se estar ciente de que se está a trazer à tona possibilidades outras de se aceder, conceber e compreender os campos do saber, seus atos e ontologias.

A investigação artística e a prática como investigação encontram reverberações contemporâneas no mundo todo em busca por caracterizações de possibilidades de enfoques metodológicos que venham ao encontro das singularidades de sua especificidade de área, de mesmo modo que também ainda necessitam estabelecer terminologias e conceitos que melhor se atenham à realidade dos campos das pesquisas em artes. Nesse sentido, o texto desse artigo tem como objetivo apresentar,

16 As palavras outro(s), outra(s) serão utilizadas, em itálico, com o intuito de dar ênfase a alsum aspeto diferenciado e amplo sobre o que se está a abordar. Esse recurso também é utilizado para ressaltar que não estou a utilizar essas palavras apenas como pronomes indefinidos. Além disso, quando também destacar palavras em itálico - que não sejam as em outro idioma estarei a provocar o leitor para que as considere como um tipo de convite à reflexão desapegada das maneiras habituais como se depara com a leitura e, assim, amplie suas perspectivas sobre o que o termo estiver a se referir em determinada parte do texto. brevemente, a metodologia de pesquisa do surrealismo etnográfico, aplicado ao contexto da pesquisa em teatro, realizada por Vargas (2018), em seu estudo de doutoramento, abordando a dramaturgia da corporeidade, a pedagogia do evento teatral e, nesse ínterim, os processos cognitivo-afetivo-significativos relacionados aos vivenciamentos estéticos entre artistas e espectadores.

\section{O EXPERIMENTO POÉTICO-TEATRAL NA PESQUISA ACADÊMICA}

O trabalho de doutoramento desenvolvido por Vargas (2018), dentre muitas de suas atividades, buscou dialogar com o campo da educação, ao trazer as reflexões emergidas a partir do que foi, neste trabalho, nomeado como sendo um experimento poético-teatral, com o intuito de desvelar como se dariam os processos cognitivo-afetivo-significativos durante o evento teatral. Por experimento poético-teatral, Vargas (2018) referiu que ele:

[...] envolveu a criação de uma partitura cênica a partir do texto Prometeu Acorrentado, de Ésquilo. Esse trabalho trata da criação e adaptação de movimentações corporais, vocais e suas inter-relações com a corporeidade a fim de se criar um fragmento de cena que não necessite ter as mesmas concepções ligadas à dramaturgia literária, nem muito menos à utilização em encenações. Esse experimento se refere a um modus operandi de que os atores dispõem para gerarem matrizes de trabalho e vivenciarem sensações que poderão ou não ser utilizadas ao longo dos seus processos criativos. Esses materiais de trabalho sobre si fornecem subsídios para que $o$ ator possa expandir suas reflexões para outros contextos e questões não necessariamente relacionados ao trabalho que está realizando naquele momento. Também considero que esta abordagem seja uma maneira pela qual os atores conseguem buscar elementos de reflexão para quaisquer questões a partir das relações que estabelecem com a sua corporeidade por meio de um modus peculiar de ir desenvolvendo o processo criativo. O experimento poético-teatral é um procedimento compreendido de muitas nuances durante o processo criativo, sendo uma delas a criação da partitura cênica. Esse é um tipo de pesquisa de campo, na qual o próprio campo é o corpo do ator. (Vargas, 2018: 32) 
Muitos autores e outros pesquisadores podem nomear este tipo de procedimento adotando outros tipos de terminologias. Entretanto, como trabalho de campo, na área da educação, sobretudo em face da realidade das pesquisas acadêmicas no Brasil, esse procedimento se tratou de uma inovação, inclusive como empiria, para os estudos nessa área, na universidade a partir da qual foi realizado. O detalhamento de todo o percurso técnico e do processo criativo que envolveram esse experimento foram essenciais para que a área da educação pudesse compreender, de maneira ampliada, como um artista pode desenvolver um tipo de pesquisa, envolvendo um processo criativo em arte, em teatro, sem apartá-lo do campo da educação.

As pesquisas que envolvem práticas em artes cênicas como seu trabalho de campo demandam singularidades que talvez não sejam tão divulgadas para as outras áreas do conhecimento (Bião, 1999, 2007, 2009; Keefe/Murray, 2007; Murray/Keefe, 2007; Kershaw/Nicholson, 2011; Parker-Starbuck/Mock, 2011; Prendergast, 2014; O'Donoghue, 2014). Mas, além disso, metodologias que investiguem reflexões surgidas por meio e/ou durante a prática artística ou o processo criativo que não se destinem apenas a abordar execução ou proposição de técnicas específicas, também são pouco difundidas, inclusive dentro das próprias pesquisas em artes cênicas no Brasil.

No caso desse experimento poético-teatral, há uma relação ontológica de seu procedimento em diálogo com o que Prendergast (2003) refere sobre solilóquio. Entretanto, no trabalho realizado por Vargas (2018), houve uma ampliação da visão de solilóquio enquanto momento reflexivo da personagem em uma peça de teatro para, também incluindo esse aspecto, considerar o solilóquio como uma espécie de instante para uma etnografia surrealista de/em criação artística. Nesse caso, o método de solilóquio é considerado como sendo um diálogo entre o $\mathrm{eu}$ e o $\mathrm{mim}^{17}$, abrindo oportunidade para um innerlogue, ou um tipo de «autodiálogo interior», uma interação que pode ser alegórica ou simbólica entre o eu atuando e o mim reflexivo, conforme o objetivo do que se esteja desenvolvendo (Vargas, 2018). Segundo Vargas (2018):

Essa abordagem pode auxiliar pesquisas qualitativas em práticas reflexivas para iluminarem a «voz interna» de suas reflexões, uma voz pré-textualizada,

17 Usarei a terminologia «mim» neste contexto, com o objetivo de caracterizar um tipo de distinção entre a identidade do artista e o seu distanciamento crítico-reflexivo enquanto desenvolve a actividade que se está a descrever neste momento do texto. pré-verbalizada, uma voz fenomenologicamente viva, um meio de re/encontrar/confessar o que está protegido pelos bastidores do inconsciente. (Vargas, 2018: 69)

Nesse sentido, se percebe que «soliloquiolizar» permite fazer pequenos retratos, evidenciar fragmentos pessoais, como uma chave ao self, uma fonte de vida no inconsciente. Considerando esse eu como expressão de um impulso interior e o mim como análise reflexiva do $e u$, uma autoalteridade para se compreender as relações consigo, com o próximo e com o mundo. A abordagem sob a via do solilóquio permite ao ator/ /ator-educador/pesquisador/artista-criador-pesquisador o distanciamento reflexivo para o desenvolvimento e análise de sua pesquisa de campo quando, neste caso, envolver seu próprio corpo, sua corporeidade, seus processos criativos (Prendergast, 2003). Esse fato evidencia tais experiências como breves fragmentos de vivenciamento. Fragmentos a comungar, os quais, por sua efemeridade, requerem uma abordagem investigativa específica que possibilite a imersão além das superfícies do momentâneo, extraindo daí caminhos para o universo profundo do não aparente, do não dito, do silêncio. Esse tipo de enfoque de pesquisa requer uma metodologia que venha ao encontro de fundamentar e dar possibilidades de que isso seja possível quando da etapa de empiria e de sua posterior fase de tradução para a escrita de pesquisa, ocorrendo esta última da maneira como for necessária a atender as potencialidades reflexivas do trabalho efetuado.

Nesse caso, o estudo desenvolvido por Vargas (2018), pensando a pesquisa acadêmica em artes cênicas, educação, ciências humanas, propiciou perceber que o solilóquio, o trabalho sobre si, o experimento poético-teatral desenvolvido como trabalho de campo podem propiciar elementos reflexivos importantes para o desenvolvimento de investigações nessas áreas. A realização do experimento poético-teatral como estudo de campo contemplou a possibilidade de realizar uma investigação empírica sobre relações que se dão por meio de/na corporeidade in loco. Esse procedimento não apenas instaurou uma proximidade entre os campos de pesquisa na área da educação e da criação artística, mas também permitiu estabelecer um modus outro para efetuar investigações em um entre-lugar para a pesquisa acadêmica. 
O conceito de surrealismo, utilizado por Vargas (2018) como embasamento para a adaptação metodológica de pesquisa em artes cênicas, tem suas origens no manifesto surrealista de meados do século Xx. Uma das propostas deste movimento defendia que a realidade vivida poderia ser inventada e, assim, poderia haver uma perspectiva outra de realidade, abrindo oportunidades para discussões a partir de outras perspectivas, mais profundas, diferenciadas, sobrepostas, justapostas (Breton, 2001). Essa outra maneira de pensar a realidade inclui a possibilidade de nos libertarmos de quaisquer tipos de normatizações de linearidades, sejam elas históricas, de ideias, ideologias, e, conforme a proposta de Vargas (2018), sobre como desenvolver uma pesquisa em artes cênicas na qual o processo de pesquisa envolva a corporeidade do artista-pesquisador, incluindo aí a possibilidade de a estética se legitimar como interface do campo da educação por meio dos processos cognitivo-afetivos e da própria pedagogia do evento teatral.

Mesmo com as especificidades estéticas e conceituais do surrealismo, foram adaptados por Vargas (2018) alguns desses princípios para aplicar o surrealismo etnográfico em uma pesquisa que demandava um experimento poético-teatral, no intuito de oferecer uma perspectiva diferenciada para um delineamento de pesquisa que se desprendesse dos laços estabelecidos pelas ciências e metodologias tradicionalmente utilizadas no Brasil, possibilitando a criação de uma abordagem que se proponha a reflexões a partir de pontos de vista diferenciados dos até então normatizados. Uma perspectiva disso foi descrita por Vargas et al. (2019) ao refletirem sobre o surrealismo etnográfico como metodologia de pesquisa para as ciências humanas. Entretanto, é importante salientar que, quando estou a me referir sobre o surrealismo, ressalto Clifford (2008) ao expor que:

Estou usando o termo surrealismo num sentido obviamente expandido, para circunscrever uma estética que valoriza fragmentos, coleções curiosas, inesperadas justaposições - que funciona para provocar a manifestação de realidades extraordinárias com bases nos domínios do exótico e do inconsciente. (Clifford, 2008: 122)

Nesse sentido, o surrealismo aplicado à pesquisa em artes cênicas, conforme efetuado por Vargas (2018), se configura como uma atividade com vista à fragmentação e à justaposição de informações/experiências dinâmicas que se sobrepõem e se movimentam constantemente, não apenas aquelas textualmente expostas, mas também aquelas que são transmitidas em patamares mais profundos como que suspensas em uma outra realidade também existente. Mais do que focar na descrição dos caminhos e situações, o pesquisador deve estar atento às reflexões que se lhe surgem nesses momentos e utilizá-las como impulsos a novas reflexões em seu percurso de pesquisa. Essa concepção de surrealismo se mostra importante a qualquer pesquisa que se desenvolva e transite por entre-espaços que necessitem de liberdade, fluidez e amplitude de voo para descobrir onde e como os sentidos e significados podem ser gerados/dinamizados, distanciando-os dos locais facilmente acionados pela observação direta e objetiva, como por exemplo, na análise superficial de um texto, nas expressões corporais externas ou na fixação da verbalização das palavras, sem percebermos singularidades que podem estar presentes em outros aspectos da vida que não sejam de caráter concreto e objetivamente observáveis (Vargas, 2018). Sobre essa peculiaridade, Clifford (2008) ajuda a compreender a metodologia surrealista ao expor que:

A realidade não era mais um dado, um ambiente natural e familiar. $O$ self, solto de suas amarras, deve descobrir o sentido onde for possível - um dilema, evocado em sua forma mais niilista e que está subjacente tanto no surrealismo quanto na etnografia moderna. (Clifford, 2008: 123).

Quando Vargas (2018) assumiu um referencial epistemológico embasado na etnografia e trazendo o surrealismo para esse ínterim, fundamentou a investigação estética de uma realidade presente em um universo não aparente, que pode também transitar por um tipo de universo imaginário, mas que também revela intenções e questões através das quais o corpo aloja suas representações. Questões essas que podem obter reflexões ampliadas a partir da compreensão das relações de alteridade e corporeidade explicadas com mais densidade no trabalho deste autor. Conforme Bussoletti (2007: 108) refere: «o surrealismo é uma arma poderosa que permite romper grades, quebrar vidraças, soltar amarras, revelar que o novo também é lugar de opção». A etnografia e o surrealismo, segundo os pontos de vista aqui adotados, conferem elementos que indicam o caminho da aproximação prática para essa abordagem. Sobre esse assunto, relaciono com Clifford (2008) quando diz que: 
Uma prática etnográfica surrealista ataca o familiar, provocando a irrupção da alteridade - o inesperado. [...] ambas são elementos no interior de um complexo processo que gera significados culturais, definições de nós mesmos e do outro. [...] momento de justaposição metonímica de sua sequência usual, um movimento de comparação metafórica no qual fundamentos consistentes para similaridade e diferença são elaborados. O momento surrealista em etnografia é aquele no qual a possibilidade de comparação existe numa tensão não mediada com a mera incongruência. Esse momento é repetidamente produzido e suavizado no processo de compreensão etnográfica. (Clifford, 2008: 152-153)

O surrealismo etnográfico é um «hibridizador» de linguagens, um matizador de possibilidades, no qual diversas instâncias de escritas de pesquisa se coadunam propondo outras perspectivas que englobam aspetos diferenciados, ressaltados por Vargas (2018), como sendo processos cognitivo-afetivos, importantes para abordar essas peculiaridades incluindo a estese, a partilha do sensível, o sinestésico, para assim considerá-los como também sendo momentos nos quais se potencializam os processos cognitivo-afetivo-significativos. Há que ter cuidado para que, ao incluir as artes como escrita-reflexivo-sensível, não torná-las meras ilustrações dos textos escritos e delimitados pelas possibilidades de uma lógica encefálico-fisiológica-racional embrutecedora dessas possibilidades. Há que perceber as artes como linguagens, como textos de si, em si e em diálogo justaposto com as discussões e reflexões a que os trabalhos utilizando o surrealismo etnográfico se proponham a efectuar.

Ao adotar a proposta do surrealismo etnográfico, segundo a perspectiva de Vargas (2018), também é possível encontrar possibilidades para que a própria noção de tempo tenha uma acepção peculiar, especialmente por estar a trabalhar em uma perspetiva de prática de pesquisa que agrega a corporeidade e traz a esta última uma necessidade de concepção de tempo particular. Tempo esse que se desprenderá das noções cronológicas e lineares e estará mais relacionado com percepções estésicas que suscitarão reflexões quando do momento de efetivação dos processos criativos dos artistas-pesquisadores que estiverem a utilizar desses procedimentos em seus estudos. Essa percepção de lidar com uma noção de tempo diferenciada abre as portas sinestésicas para um processo que se distancia, inclusive, dos conceitos tradicionais sobre etnografia, mesmo que se esteja a lidar com uma abordagem em solilóquio, como no estudo de Vargas (2018). Nesse caso, a inspiração para que essa metodologia se desenvolva em consonância com características etnográficas se baseou no que fora proposto por Clifford (2008):

O termo etnografia, tal como estou usando aqui, é diferente, evidentemente, da técnica de pesquisa empírica de uma ciência humana que na França foi chamada de etnologia, na Inglaterra, de antropologia social e na América, de antropologia cultural. [...] O rótulo etnográfico sugere uma característica atitude de observação participante entre os artefatos de uma realidade cultural tornada estranha. [...] pesquisador no campo, que tenta tornar compreensível o não familiar, tendia a trabalhar no sentido inverso, fazendo o familiar se tornar estranho. (Clifford, 2008: 125)

Com o intuito de compreender etnografia sob outro ponto de vista, há que perceber que estamos a trabalhar em um processo complexo de estranhamento e que se torna mais complexo ainda quando, como apresentado por Vargas (2018), o campo for o próprio corpo do investigador, a sua corporeidade. A partir de Clifford (2008) e inspirado nas adaptações das propostas deste autor feitas por Bussoletti (2007), Vargas (2018) propôs uma abordagem para este tipo de metodologia de pesquisa que viesse ao encontro das especificidades das artes cênicas, sobretudo, quando a investigação for pautada por aspetos que envolvam a corporeidade e os processos criativos relacionados com o treinamento físico desses artistas. Quando se está a pensar em uma abordagem investigativa que proponha um meio outro para o desenvolvimento do trabalho de campo em uma área do conhecimento em que se agregam os processos criativos das artes cênicas, os aspetos relacionados à corporeidade e ao treinamento físico dos artistas dessa área, há que perceber que é necessário permear terrenos onde, segundo Vargas (2018), o pragmatismo, a linearidade, o positivismo e o excesso de objetividade não se permitem transitar, uma vez que a abordagem de suas variáveis não penetra em espaços onde a sensorialidade, o inconsciente, a sinestesia e a emoção se fundamentam como campos de conceitos esteticamente definidos.

O surrealismo etnográfico é uma possibilidade outra para abordagens de pesquisa que pretendam investigar, compreender e refletir sobre aspetos relacionados à sinestesia, à sensibilidade, à sensorialidade, à afetividade, aos subtextos relacionados à corporeidade, pois, no surrealismo etnográfico se incorporam instâncias de análise que valorizam o fragmentar. Esses aspetos são aqui trazidos por meio de uma aplicação do surrealismo etnográfico, a partir de uma perspectiva estética nas artes 
cênicas, na qual se considera a estética como campo epistemológico que requer um modus operandi mais amplo e passível de desenvolver seus trabalhos, explicando-os em diálogo com o que Vargas (2018) referiu sobre as relações de/em corporeidades e os processos cognitivo-afetivo-significativos.

No surrealismo etnográfico, os fragmentos, suas dispersões e movimentos são mais importantes do que quaisquer tipos de elaborações e demarcações de possibilidades. Analisar as experiências concebendo-as como transpassadas pelo fragmentar, buscando em cada um desses fragmentos de sensações, experiências, sentidos, sinestesias e significados, potenciais reflexivos para se compreender as relações com o entorno de maneira ampliada, possibilita aproximar do que Benjamin (2013) parece sugerir quando menciona que:

O valor dos fragmentos de pensamento é tanto mais decisivo quanto menos imediata é a sua relação com a concepção de fundo, e desse valor depende o fulgor da representação [...]. A relação entre a elaboração micrológica e a escala do todo, de um ponto de vista plástico e mental, demonstra que o conteúdo de verdade (Wahrheitsgehalt) se deixa apreender apenas através da mais exata descida ao nível dos pormenores de um conteúdo material (Sachgehalt) [...]. (Benjamin, 2013: 17)

Concordando com o autor supracitado e trazendo essa discussão para um diálogo com a proposta do surrealismo etnográfico como metodologia de pesquisa em artes cénicas proposta por Vargas (2018), se torna possível perceber que existe a possibilidade de um vasto campo a ser desvelado a partir dos fragmentos, sem haver, necessariamente, uma relação objetiva imediato-cognitiva do fragmento com o que se esteja buscando de maneira mais ampla naquele momento. Isso indica um meio de olhar os fragmentos, em cada um, buscando em todos os seus instantes, elementos de subsídios que guardem sementes de sentidos dispostos a germinarem e/ou a se moverem (Vargas, 2018). A relação não-direta do fragmento com o que parece se estar a buscar no instante investigativo - ou criativo-investigativo, quando relaciono esse facto aos processos criativos em artes, sem nunca distanciá-los da educação, segundo a acepção assumida por Vargas (2018) - ressalta o caráter importante de elementos ricos que cada fragmento contém. Entretanto não os explicita de maneira direta, objetiva, uma vez que os fragmentos se potencializam na instância das subjetividades, nos planos do inconsciente.
A relação entre essa elaboração significativo-afetiva do fragmento com o amplo ressalta que ele contém em si elementos já vivenciados, experienciados, tocados por potenciais que lhe deixaram rastros de possibilidades em latências pré-dispostas ao desvelamento, auras de sentidos a espargir, desde que se deseje e se esteja apto a reacessá-los (Vargas, 2018). No que é referido acima a partir da citação de Benjamin (2013), a temática está relacionada com o pensamento mas, no trabalho desenvolvido por Vargas (2018), essa visão foi ampliada para o campo da corporeidade, aos fragmentos sinestésicos em tais experiências. Os fragmentos sinestésicos em corporeidade possuem subsídios que se nos revelam por meios outros que não apenas aos que seriam viáveis de descrição ou menção no que é possível dentro dos parâmetros das palavras textualmente organizadas. Esses argumentos, apresentados por Vargas (2018), ressaltam uma necessidade característica do surrealismo etnográfico em transgredir a escrita tradicional em palavras para agregar elementos em estética como potenciais amplos para dar passagens às reflexões emergidas a partir do processo criativo-investigativo.

Seguindo ainda com o que Benjamin (2013: 23) parece indicar, há que perceber que «as ideias são constelações eternas, e se os elementos se podem conceber como pontos em tais constelações, os fenômenos estão nelas simultaneamente dispersos e salvos». Assim, partindo desse autor, se percebe que as ideias ontologicamente se dispersam no orbe do conhecimento e também das experiências, dos vivenciamentos, propiciando vias de acesso para que sejam acessadas conforme nos aprouver. Esse tipo de característica vem ao encontro de um posicionamento relacionado à tomada de atitude do ponto de vista de encarar o campo empírico em consonância com os princípios do surrealismo etnográfico, ou seja, se desviando das normatizações de realidade e objetividade na concatenação de ideias e seus sentidos, conforme as normatizações tradicionais o fazem na maioria das produções acadêmicas desta área no Brasil. Na concepção adotada por Vargas (2018), por tratar de um aprofundamento que necessita pairar por-entre o inconsciente estético - conceito relacionado com as propostas de Rancière (2009) - valorizar o fragmento e encará-lo sob o aspeto de constelação - conforme Benjamin (2013) parece referir em suas abordagens - se mostra importante para compreender de maneira ampla e profunda os matizes que mediam as potencialidades de discussões que se proponham a ser geradas a partir de pesquisas que se desenvolvam por meio do surrealismo etnográfico. 
Há que se enfatizar que a metodologia do surrealismo etnográfico aqui apresentada como delineamento de pesquisa aplicado às artes cénicas não se refere ao desenvolvimento de uma investigação utilizando parâmetros artísticos e estéticos, conforme os caracterizados nas obras surrealistas criadas por alguns artistas. Essa opção poderá ocorrer e será legítima, caso se opte por ela. Porém, a proposta de Vargas (2018) para essa metodologia na pesquisa em artes performativas é uma expansão da abordagem de Clifford (2008) e da proposta de Bussoletti (2007), tendo por base alguns dos princípios relacionados com o movimento surrealista, conforme exposto por Breton (2001), nesse último, sobretudo nas interfaces relacionadas com os diálogos do surrealismo com a psicanálise freudiana. O que fora proposto por Vargas (2018) permite uma abordagem artística em quaisquer opções estéticas e poéticas, de acordo com os ensejos do pesquisador e/ou artista que esteja a se propor a desenvolver seu trabalho dessa maneira. A questão surrealista vai além das observações e trabalhos sob essa (ou nessa) estética, ela se refere a algo a mais, de análise e reflexão, um modus operandi para se compreender o mundo e que se abre a outros tipos de justaposições e inferências investigativas que permitam o trânsito de pesquisa em uma atmosfera de realidade outra que não necessariamente as tradicionalmente instituídas e/ou institucionalizadas. No surrealismo, o acesso e valorização daquilo que é protegido pelos véus do inconsciente emerge como fonte de reflexão (Vargas, 2018). A percepção dos elementos sinestésicos durante o processo criativo se potencializa por meio da asserção das potencialidades existentes nas dispersões dos fragmentos vivenciados por meio da corporeidade e do que há de instigante em cada um destes fragmentos.

Ao aproximar as concepções de Breton (2001) e Clifford (2008) às reflexões de Bussoletti (2007), a proposta de Vargas (2018) permitiu uma ampliação ainda mais profunda e abrangente para essa abordagem, possibilitando que esse tipo de delineamento se abrisse a quaisquer áreas do conhecimento em que pesquisa, campo de pesquisa e pesquisador estejam mútua, ativa e intrinsecamente a fazer parte deste processo, sendo o próprio processo, vivenciando-o, sem objetivos de afastar-se para descrevê-lo de maneira distanciada. Mas a estar inserido nele, experienciando-se para experienciá-lo, para vivenciá-lo, compreendê-lo, compreender-se nesse processo e, assim, desenvolver a pesquisa sob um ponto de vista outro, liberto das amarras tradicionalmente estabelecidas pelo meio académico e, inclusive, a abrir possibilidades para o corpo vir a se tornar o campo de estudo a partir de uma ótica diferenciada das que são efectuadas em outras metodologias investigativas (Vargas, 2018). Essa peculiaridade é importante de ser ressaltada, especialmente, no que se refere às pesquisas nas artes da cena, uma vez que esse tipo de abordagem costuma ser uma prática comum nessa área, porém ainda não explicitada epistemológica e metodologicamente, conforme Vargas (2018) efetuou.

\section{CONSIDERAÇÕES FINAIS}

O surrealismo etnográfico, aplicado à pesquisa em artes cênicas por Vargas (2018), está longe de ser uma metodologia já fechada e detalhadamente descrita, uma vez que ainda está em desenvolvimento pelo grupo de investigação no qual este estudo se originou (Vargas et al., 2019). Entretanto, já a partir deste primeiro trabalho nesta área se pode perceber uma proposta de método potencialmente novo para as artes performativas, oferecendo subsídios que possibilitem reflexões ampliadas a partir dos elementos encontrados durante o trabalho de campo, quando este envolver processos criativos, vivenciamentos estéticos e aprofundamentos investigativos relacionados com a sinestesia das relações de/em corporeidades, assim como dos elementos estésicos relacionados à contemplação estética e ao evento teatral.

A necessidade de buscar fundamentações que caracterizem terminologias e um vocabulário que atenda às especificidades das artes performativas, em relação aos seus procedimentos metodológicos de pesquisa, de acordo com um arcabouço teórico-reflexivo, coadunado às práticas dos processos criativos e dos trabalhos práticos dos profissionais dessa área, se configura como extremamente importante nos dias de hoje. No trabalho realizado por Vargas (2018), a criação do experimento poético-teatral recebeu esta nomenclatura por aproximar o conceito de poiesis ao processo criativo de um ator que estava em busca de reflexões sobre as relações de/entre corporeidades. Além disso, esse procedimento de trabalho de campo foi considerado como experimento, com o intuito de trazer à grande área das ciências humanas o trabalho de campo como experimentação, como processo, como instância que não se fixaria enquanto classificação já taxonomicamente normatizada de acordo com outros métodos de pesquisa nessa área. Deixar o processo em aberto e como processo empírico, por meio de um trabalho criativo em arte, «soliloquiolizado» como catalisador reflexivo, potencializou a estética 
como campo do conhecimento com um modus operandi particular, o qual possibilitou ampliar a compreensão sobre os processos cognitivo-afetivo-significativos e perceber, assim, o quão educativo o trabalho de um ator já o é em sua própria área do conhecimento.

Mas acredito que, acima de tudo, esse artigo oferece uma possibilidade para que a área das artes performativas se abra e se sinta instigada a buscar metodologias de pesquisa que estejam em maior consonância com as necessidades empírico-reflexivas dos artistas-pesquisadores contemporâneos, assim como de potencialidades e abordagens outras para as reflexões de seus estudos. No que se refere ao surrealismo etnográfico, ele serviu como potenciador epistemológico para que o processo empírico realizado por meio do experimento poético-teatral «soliloquiolizado» pudesse palpar os potenciais reflexivos existentes em esteses fragmentares e trazê-los à tona como elementos tangíveis às discussões e reflexões originadas a partir dessa pesquisa. Apesar disso tudo, considero que ainda seja necessário o surrealismo etnográfico ser aplicado, desenvolvido e aperfeiçoado em outras pesquisas nesta área e até, quem sabe, servir de mote para que sejam criadas outras metodologias de pesquisas que hibridizem diferentes referenciais metodológicos e necessidadescrítico-criativo-reflexivasdeseusartistas-criadores-pesquisadores em sintonia com as especificidades de área das artes performativas nos dias de hoje. Para isso, as pesquisas nesta área necessitam estar abertas aos avanços, inovações e de possibilidades outras às necessidades contemporâneas dos profissionais que se proponham a desenvolver seus estudos nessa área do conhecimento.

\section{REFERÊNCIAS BIBLIOGRÁFICAS}

BENJAMIN, Walter (2013), Origem do drama trágico alemão, Belo Horizonte/MG, Autêntica.

BIÃo, Armindo (2009), Etnocenologia e a cena baiana: Textos reunidos, Salvador/BA, P \& G Gráfica e Editora.

- (2007), Artes do corpo e do espetáculo: Questões de etnocenologia, Salvador/BA, P \& A.

- (1999), «Aspectos epistemológicos e metodológicos da etnocenologia: Por uma cenologia geral», in Memória ABRACE I: ANAIS do I Congresso Brasileiro de Pesquisa e Pós-Graduação em Artes Cênicas, Salvador/Bahia, UFBA, pp. 364-367.

BRETON, André (2001), Manifesto do Surrealismo, Rio de Janeiro/RJ, Nau Editora.

BUSSOLETTI, Denise Marcos (2007), Infâncias monotônicas - Uma rapisódia da esperança-Estudo psicossocial cultural crítico sobre as representacões do outro na escrita de pesquisa, tese de doutorado do programa de pós-graduação em Psicologia, Pontifícia Universidade Católica do Rio Grande do Sul, Porto Alegre.

CLIFFORD, James (2008), A experiência etnográfica: antropologia e literatura no século xx, Rio de Janeiro, Editora UFRJ.
KEEFE, John, e MURRAY, Simon (eds.) (2007), Physical theatres: a critical reader, New York/USA, Routledge.

KERSHAW, Baz, e NICHOLSON, Helen (eds.) (2011), Research methods in theatre and performance, Edinburgh/ /Scotland, Edinburgh University Press.

MURRAY, Simon, e KEEFE, John (eds.) (2007), Physical theatres: a critical introduction, New York/USA, Routledge. O'DONOGHUE, Donal (2014), «Doing arts-based educational research for the public good: An impossible possibility?», International Journal of Education $\mho$ the Arts, 15(SI 2.3), vol. 15, special issue 02, pp. 1-16, disponivel em http://www.ijea.org/v15si2/, consultado em 26 de julho de 2016.

PRENDERGAST, Monica M. (2003), «I, Me, Mine: Soliloquizing as Reflective Practice», International Journal of

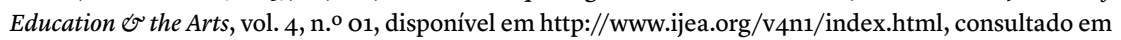
26 de julho de 2016.

- (2014), «I contain multitudes: The challenges of self-representation in arts-based educational research» International Journal of Education \& the Arts, 15 (SI 2.2), vol. 15, special issue 2, pp. 1-17, disponivel em http://www.ijea.org/v15si2/, consultado em 26 de julho de 2016.

RANCIÈRE, Jacques (2009), O inconsciente estético, São Paulo/SP, Editora 34

vARGAS, Vagner de Souza (2018), Dramaturgia da corporeidade: A pedagogia do evento teatral, tese de doutorado, programa de pós-graduação em Educação, doutorado em Educação, Universidade Federal de Pelotas (UFPEL).

VAR Gas, Vagner de Souza, DUARTE, Krischna Silveira, Bussoletti, Denise Marcos, vieira, Daniel da Silva, e GAUDENZI, Mariana Vargas (2019), «Outra metodologia para as pesquisas em ciências humanas», Revista Educação e Cultura Contemporânea, n. ${ }^{\circ}$ 44, vol. 16, pp. 318-341.

\section{VAGNER DE SOUZA VARGAS}

\section{-}

Doutor em Educação pelo programa de pós-graduação em Educação da Universidade Federal de Pelotas (UFPEL). Actor, licenciado em Teatro. 